chlorids abgeleitet, sonst konnle Natron nicht nachgewiesen werden. Bei der Gersle hat man sich mit der Prüfung der phosphorsauren Alkalien durch Reagentien begnügt, es fand sich kein Natron. In Roggenasche fand ich selust die Menge des Kaliumplatinchlorids ganz der des Kaliumchlorids entsprechend. Nothwendig mufs das Getreide Natron enthalten, denn woher sollten wir das Natron im Blute bei Brodnahrung haben. Es könnte blofs aus dem Kochsalze der Speisen kounmen, aber da alle unsere Bodenauszüge Kochsalz enthalten, so glaube ich, daIs Kochsalz bei der Einäscherung verflüchtigt wird. Ich finde fast nie Chlor und Schwefelsüure in den Aschen, letatere nur bei Leguminosenfrüchten in bedeutender Jlenge, in Roggen gar nicht. Bemerken mufs ich noch, dafs unser Boden durch Verwitterung von Porphyren entstanden ist, in denen allerdings nur Kalifeldspalh vorkommt, der jedoch, wie behauplet ivird, immer etwas Natron enthalten soll.

\title{
Analyse von Dolerit und Halbopal ;
}

von Francis Whrightson aus Birmingham.

\section{Dolerit.}

Die qualitative Analyse ergab folgende Bestandtheile : Natron, Kali, Magnesia, Kalk, Eisenoxydul, Thonerde, Schwefelsüure, Kieselerde und aufserdem noch Hydratwasser.

$0,6963 \mathrm{Grm}$. des feingepulverten, bei $100^{\circ}$ getrockneten Minerals verloren in der Rolhglühhitze 0,0135 Grm. Wasser. Der Wassergehalt beträgt mithin $1,93 \mathrm{pC}$.

Das fein gepulverte, bei $100^{\circ}$ getrocknete Mineral wurde mehrere Tage lang mit starker Salzsäure digerirt, bis es gallertartig wurde und gänzlich aufgeschlossen schien. 2,6120 Grm. 
liefsen einen Rückstand von 1,8940 Grm., der indels keine reine Kiesclerde war, denn nachdem er mit kohlensaurem NatronKali geschmolzen war, fand sich in demselben aufser Kieselerde noch bedeutende Mengen von Eisenoxyd oder Thonerde, so wie auch elwas Kalk. Die daraus' erhaltene reine Kieselerde wog 1,371 Grm., betrug also 52,5 pC.

Dje saure Lösung wurde zur Bestimmung aller Bestandtheile, mit Ausnahme von Eisenoxydul, Thonerde und Kieselerde benutzt; zur Bestimınung der übrigen aber cine neue Portion des vlinerals mit kohlensaurem Nalron - Kali geschmolzen.

1,522 Grm. des Minerals mit kohlensaurem Natron-Kali geschmolzen lieferten $0,809 \mathrm{Grm}$. Kieselerde $(53,12 \mathrm{pC}$.). 0,299 Eisenoxyd, was 17,65 pC. Eisenoxydul enlspricht; ferner 0,094 Thonerde, also 6,14 pC.

2,612 Grm. des Minerals mit Salzsäure behandelt lieferten 0,0635 schwefelsauren Baryt, was 0,86 pC. Schwefelsünre entspricht; man erhielt 0,458 kohlensauren Kalk, durch Glühen des oxalsauren Kalkes, also 9,89 pC. Kalk. Die Magnesia wurde durch Baryt gefält, und von einem Ueberschufs des letztern durch Schwefelsäure befreit; 0,384 der so erhaltenen schwefclsauren Magnesia entsprechen 6,66 pC. Magnesia.

Das Gewicht der Chlormetalle betrug, nachdem der überschüssige Baryt durch Schwefelsäure entfernt war, nach dem Glühen 0,143. Die wässrige Lösung derselben, mil Platinchlorid und Weingeist behandelt, lieferte 0,248 Chlorplatinkalium; 1,83 pC. Kali entsprechend; es blieben also 0,067 Grm. Chlornatrium, die $1,33 \mathrm{pC}$. Natron entsprechen.

Man liann in diesem Mineral alle Schwefelsäure mit Kalk zu Gyps verbunden annehınen, weil Wasser, womil das feingeriebene Mineral behandelt wurde, deulliche Reactionen auf Kalk und Schwefclsäurc giebt.

Das Mlinoral enthält also : 


\begin{tabular}{|c|c|c|}
\hline Kieselerde &  & . 53,12 \\
\hline Eisenoxydul & • & . 17,65 \\
\hline Thonerde . & & 6,14 \\
\hline Schwefelsäur & e & 0,96 \\
\hline Kalk & & 9,89 \\
\hline Magnesia . & $\cdot$ & 6,66 \\
\hline Kali & & 1,83 \\
\hline Natron & & 1,33 \\
\hline Wasser & & 1,93 \\
\hline Terlust & & 0,59 \\
\hline
\end{tabular}

II. IIalbopal vom Schiffenberg in der Gegend von Gie/sen.

Das fuin gepulverte Mineral wurde durch mehrtägiges Digeriren mil starker Salzsäure nur unvollkonımen aufgeschlossen, denn der Rückstand, wohl ausgewaschen, gab nach dem Schmelzen mit kohlensaurem Natron - Kali noch Reactionen auf Eisenoxyd und Thonerde. Die saure Lösung enthielt folgende Bestandtheilc : Scluwefelsäure, Nalron, Kali, Magnesia und Eisenoxydul. Um zu sehen, ob das Eisen in dem Mineral als Oxydul oder als Oxyd, vielleicht auch als beides enthalten sey, wurde ein anderer Theil des Minerals in einer verschlossenen Flasche, um dic Luft abzuhalten, mit Salzsäure digerirt, und die Lösung mit Ferrocyankalium und Ferridcyankalium untersucht; man fand so wenig Eisenoxyd, dafs man annehmen kann, alles Eisen sey als Oxydul vorhanden.

Das bei $100^{\circ}$ getrocknete Mineral verlor beim Erhitzen in einer Glasröhre noch Wasser.

Zur quantitativen Bestinumung der Alkalien wurde das fein gepulverte Mineral mit seinem vierfachen Gewichte Flufsspath gemengt, und nach der von H. Rose angegebenen Methode behandelt. Zur quantitativen Bestimmung der übrigen Bestandtheile wurde das Mineral mit kohlensaurem Natron geschmolzen, 
wodurch die Kieselerde ganz rein und weifs und vollkommen löslich in Kalilauge abgeschieden wurde.

0,937 Grm. des fein gepulverten, bei $100^{\circ}$ getrockneten Minerals verloren, im bedcckten Tigel zum Rothglühen erhitžt, 0,026 Grm. oder 2,73 pC. Wasser.

Der Rest, mit kohlensaurem Natron geschmolzen, ergab 0,845 Grm. Kieselerde (90,20 pC.). 0,043 Grm. Eisenoxyd, die 4,11 pC. Eisenoxydul entsprechen, 0,018 Grm. Thonerde (1,86 ${ }^{\circ}$ C.). 0,022 Grm. zweibasisch phosphorsaure Magnesia, entsprechend 0,008 Grm. Magnesia $(0,86 \mathrm{pC}$.) und 0,009 schwefelsauren Baryt, der 0,003 Schwefelsäure enthäil, also 0,31 pC.

1,506 Grm. des Minerals, durch Behandeln mit Flufsspath und Schwefelsäure zersetzt und so lange ausgewaschen, bis nur noch Gyps durch das Filter ging, wurden auf gewöhnliche Weise von Eisen, Thonerde und Naguesia gelrennt, zur Trockne eingedampft und geglüht. Der Rückstand $0,067 \mathrm{G}_{i} \mathrm{~m}$. bestand aus scliwefelsauren Alkalien. Dic Lösung dessellıen gab mil Weingeist und Platinchlorid 0,064 Grm. Chlorplatinliulium, entsprechend 0,012 Grm. Kali $(0,80 \mathrm{pC}$.), welches 0,033 Grm. schwefelsaurem Kali entspricht; es bleibt also 0,034 Grm. schwefelsaures Natron, 0,015 Grm. Natron (0,90 pC.) enlsprechend.

Das Mineral enthält also :

\begin{tabular}{|c|c|}
\hline Kieselerde & 90,20 \\
\hline Wasser & 2,73 \\
\hline Eiscnoxydul . & 4,11 \\
\hline Thonerde & 1,86 \\
\hline Magnesia & 0,86 \\
\hline Kali . & 0,80 \\
\hline Natron & 0,90 \\
\hline Schwofelsäure & 0,31 \\
\hline
\end{tabular}

